\title{
In vitro anthelmintic effects of cysteine proteinases from plants against intestinal helminths of rodents
}

\author{
Gillian Stepek $^{1+}$, Ann E. Lowe ${ }^{1}$, David J. Buttle ${ }^{2}$, Ian R. Duce ${ }^{1}$ \\ and Jerzy M. Behnke ${ }^{1 *}$ \\ ${ }^{1}$ School of Biology, University of Nottingham, NG7 2RD, UK: ${ }^{2}$ Academic \\ Unit of Molecular Medicine, University of Sheffield Medical School, \\ S10 2RX, UK
}

\begin{abstract}
Infections with gastrointestinal (GI) nematodes are amongst the most prevalent worldwide, especially in tropical climates. Control of these infections is primarily through treatment with anthelmintic drugs, but the rapid development of resistance to all the currently available classes of anthelmintic means that alternative treatments are urgently required. Cysteine proteinases from plants such as papaya, pineapple and fig are known to be substantially effective against three rodent GI nematodes, Heligmosomoides polygyrus, Trichuris muris and Protospirura muricola, both in vitro and in vivo. Here, based on in vitro motility assays and scanning electron microscopy, we extend these earlier reports, demonstrating the potency of this anthelmintic effect of plant cysteine proteinases against two GI helminths from different taxonomic groups - the canine hookworm, Ancylostoma ceylanicum, and the rodent cestode, Rodentolepis microstoma. In the case of hookworms, a mechanism of action targeting the surface layers of the cuticle indistinguishable from that reported earlier appears to be involved, and in the case of cestodes, the surface of the tegumental layers was also the principal location of damage. Hence, plant cysteine proteinases have a broad spectrum of activity against intestinal helminths (both nematodes and cestodes), a quality that reinforces their suitability for development as a muchneeded novel treatment against GI helminths of humans and livestock.
\end{abstract}

\section{Introduction}

Plant extracts have been used for centuries throughout the world, but particularly in developing countries, as traditional treatments for many illnesses, including parasitic infections (Waller et al., 2001; Giday et al., 2003). The introduction of synthetic chemotherapeutic drugs resulted in less interest being shown in these natural therapies until very recently, when there has been a resurgence in the interest of using natural products as treatments against many parasitic diseases, including

*Fax + 441159513251

E-mail: jerzy.behnke@nottingham.ac.uk

${ }^{+}$Current address: Institute of Comparative Medicine, Faculty of Veterinary Medicine, University of Glasgow, G61 1QH, UK those caused by worms (Hammond et al., 1997; Githiori et al., 2003; Anthony et al., 2005; Hounzangbe-Adote et al., 2005). This renewed interest is largely due to the need for alternative treatments with novel mechanisms of action as a result of the rapid and widespread development of resistance to all three current classes of anthelmintics in many species of parasitic helminths, but particularly those species found throughout the gastrointestinal (GI) tract of livestock (Waller, 1986; Gill \& Lacey, 1998; Geerts \& Gryseels, 2000; Kaminsky, 2003).

The crude latex of papaya (Carica papaya) (Berger \& Asenjo, 1940) and fig (Ficus species) (Robbins, 1930), and fruit of pineapple (Ananas comosus) (Berger \& Asenjo, 1939) were shown to digest the cuticle of Ascaris suum, and hence kill the nematode, in vitro. However, it was not until much later that this mechanism was described in 
more detail and was shown to be dependent upon the cysteine proteinases found in the latex or fruit of these plants (Stepek et al., 2005, 2006, 2007a). These recent studies have employed three different rodent GI nematodes, Heligmosomoides polygyrus (in the small intestine), Trichuris muris (in the large intestine or caecum) and Protospirura muricola (in the stomach), and we were interested to know more about the extent of the spectrum of activity of these enzymes. To begin to answer this, we examined the in vitro anthelmintic effect of cysteine proteinases from papaya, pineapple, fig and kiwi fruit (Actinidia chinensis) against the canine hookworm, Ancylostoma ceylanicum (found in the small intestine of dogs and humans, but maintained in the laboratory through hamsters), and the rodent cestode, Rodentolepis microstoma (found attached in the bile duct in the liver, with the strobila stretching down the bile duct and into the small intestine of mice).

\section{Materials and methods}

\section{Parasites}

The hookworm, A. ceylanicum, was maintained in hamsters, as described by Garside \& Behnke (1989). In hamsters, the adult worms develop from infective L3 within 17 days of infection. The hamsters were given food and water ad libitum, and all animal procedures were carried out in accordance with Home Office Licence number 40/2621, and under the regulations of the Animals (Scientific Procedures) Act, 1986. Infected hamsters were killed by exposure to $\mathrm{CO}_{2}$, and the entire small intestine was removed and placed in a Petri dish containing pre-heated $\left(37^{\circ} \mathrm{C}\right)$ Hanks' balanced salt solution (HBSS), where it was opened longitudinally with a pair of blunt-ended dissecting scissors and placed at $37^{\circ} \mathrm{C}$ for $1-2 \mathrm{~h}$. The adult male and female worms were collected separately, counted and washed in HBSS.

The tapeworm, R. microstoma, was maintained in BKW mice and flour beetles of the species, Tribolium confusum. The mice were given food and water ad libitum, and all animal procedures were carried out in accordance with Home Office Licence number 40/2621, and under the regulations of the Animals (Scientific Procedures) Act, 1986. The mice were killed by exposure to $\mathrm{CO}_{2}$, and the anterior small intestine, together with the bile duct and associated sections of the liver, were removed, placed in a Petri dish containing pre-heated $\left(37^{\circ} \mathrm{C}\right) \mathrm{HBSS}$, and opened with a pair of blunt-ended dissecting scissors. The tissues were placed at $37^{\circ} \mathrm{C}$ for $1-2 \mathrm{~h}$ and then the adult male and female worms were collected separately, counted and washed in HBSS.

\section{Enzymes}

The enzymes used throughout this in vitro study were the crude latex from papaya (C. papaya; Sigma, UK), the pure enzymes, papain (from the papaya plant, C. papaya; Merops (http:/ / merops.sanger.ac.uk/) identifier C01.001; Sigma) and ficin (from the fig plant, Ficus carica; C01.006; Sigma), and stem bromelain (C01.005) from the stem of the pineapple plant $(A$. comosus; Hong Mao Biochemicals
Company, Thailand). Actinidain (C01.007) was retrieved by acetone precipitation of kiwi fruit (A. chinensis) pulp. All the enzyme preparations were standardized by activesite titration with the cysteine proteinase-specific inhibitor, E-64 (Stepek et al., 2005), and all the concentrations described in the text below are for the active enzyme. Immediately prior to use, the enzymes were diluted into HBSS containing $16 \mathrm{mM}$ cysteine base.

\section{In vitro assessment of anthelmintic efficacy of plant cysteine proteinases}

Four adult male and female worms of A. ceylanicum were incubated in four-well plates (one male and one female worm per well) with the following enzyme concentrations in Hanks' saline with $16 \mathrm{mM}$ L-cysteine: $25 \mu \mathrm{M}$ papaya latex, $25 \mu \mathrm{M}$ papain, $9 \mu \mathrm{M}$ ficin, $22.5 \mu \mathrm{M}$ stem bromelain and $30 \mu \mathrm{M}$ actinidain. Four male and female control worms (one male and one female worm per well) were incubated with Hanks' saline with $16 \mathrm{mM}$ L-cysteine or Hanks' saline alone. The worms were incubated at $37^{\circ} \mathrm{C}$ for $2 \mathrm{~h}$, and their motility was recorded every $15 \mathrm{~min}$ using a motility scale from 0 to 5 , where 0 is completely immobile and 5 is highly active (Stepek et al., $2005,2006)$. In a separate experiment, adult worms were incubated for $2 \mathrm{~h}$ with the same active enzyme concentrations as described above. Worms were removed every $30 \mathrm{~min}$ and immediately fixed with $2.5 \%$ glutaraldehyde in $0.15 \mathrm{M}$ phosphate buffer, $\mathrm{pH} 7.2$ for $1 \mathrm{~h}$. These worms were then prepared for scanning electron microscopy, as described previously (Stepek et al., 2005).

Experiments with mature $R$. microstoma were carried out in a similar way, except that the active enzyme concentrations used were $25 \mu \mathrm{M}$ papaya latex, $9 \mu \mathrm{M}$ ficin, $90 \mu \mathrm{M}$ stem bromelain and $30 \mu \mathrm{M}$ actinidain.

\section{Statistical analysis}

Changes in motility were analysed by repeated measures ANOVA (general linear model (GLM)) in SPSS (version 12.0.1; SPSS Inc., Chicago, Illinois, USA) on the raw data, with time after introduction of experimental treatments as the within-subject factor, and treatment (papaya latex, Hanks' saline, etc.) as the between-subject factor. The analysis was confined to all the enzyme treatments with cysteine and to Hanks' saline + cysteine, excluding the control Hanks' saline treatment without cysteine. The data for $A$. ceylanicum (fig. 1) met the requirements of sphericity (Mauchley's test of sphericity; $W=0.132, P=0.18$ ), whereas that for $R$. microstoma (fig. 2 ) did not and, in this case, we used the Huynh-Feldt adjustment to the degrees of freedom to interpret significance on the side of caution. Tukey's HSD test was used to determine homogeneous subsets of treatment.

\section{Results}

\section{Effects of plant cysteine proteinases on worm motility}

When A. ceylanicum was incubated with all the plant cysteine proteinases detailed above, with the exception of actinidain, there was a rapid decline in the motility of the 


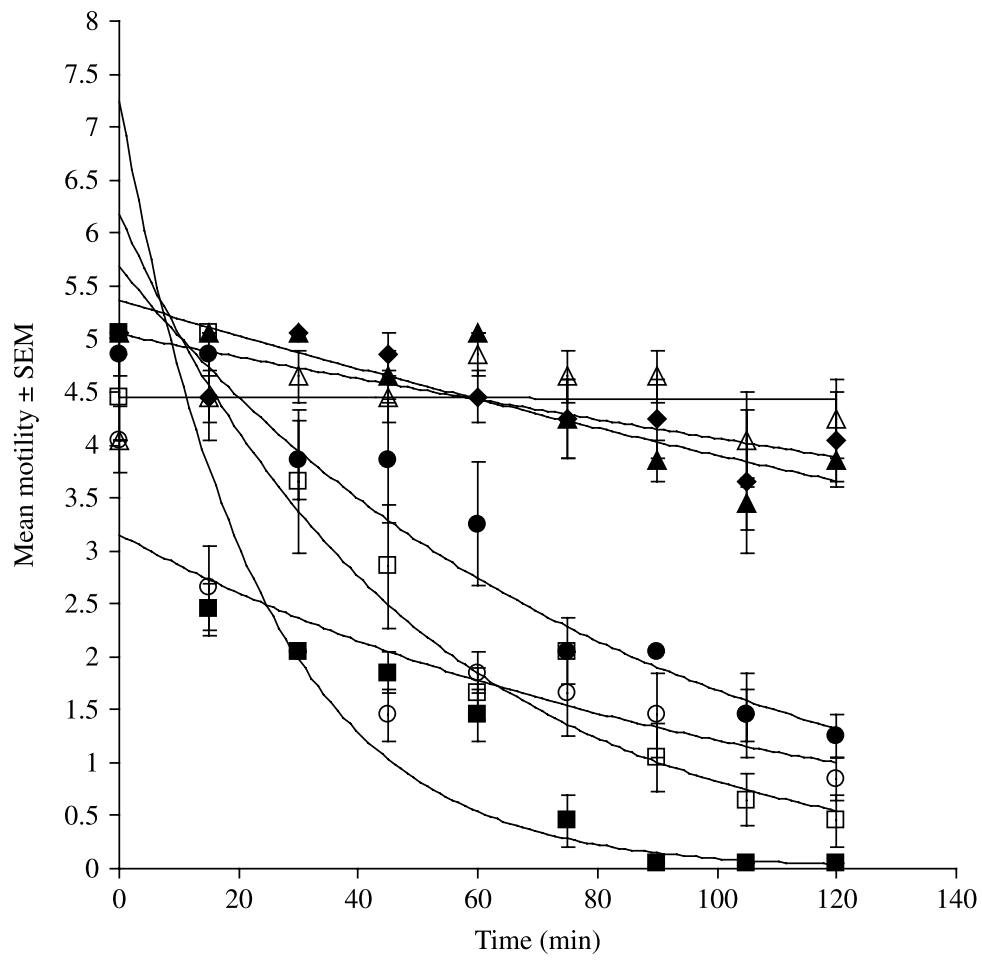

Fig. 1. The motility of Ancylostoma ceylanicum adult worms exposed to plant cysteine proteinases in vitro. Adult worms of A. ceylanicum were incubated with $25 \mu \mathrm{M}$ papaya latex, $25 \mu \mathrm{M}$ papain, $9 \mu \mathrm{M}$ ficin, $22.5 \mu \mathrm{M}$ stem bromelain, $30 \mu \mathrm{M}$ actinidain (all in Hanks' balanced salt solution containing $16 \mathrm{mM}$ L-cysteine) or Hanks' saline with or without $16 \mathrm{mM} \mathrm{L-cysteine} \mathrm{(as} \mathrm{controls).} \mathrm{Motility} \mathrm{declined} \mathrm{rapidly} \mathrm{in} \mathrm{the}$ presence of all cysteine proteinases examined, except actinidain, while no significant change in activity was evident for the worms incubated in Hanks' saline, with or without cysteine. $\mathbf{\square}$, papaya latex; $\square$, papain; $\bullet$, stem bromelain; $\bigcirc$, ficin; $\boldsymbol{\Lambda}$, actinidain; $\Delta$, Hanks' + cysteine; $\bullet$, Hanks'. Error bars represent the standard error of the mean $(n=5)$.

worms (from 15 to $30 \mathrm{~min}$ post-incubation), resulting eventually in the death of these worms (fig. 1). The motility declined with time $\left(F_{8,192}=79.9, P<0.001\right)$, and there was a highly significant main effect of treatment $\left(F_{5,24}=87.6, P<0.001\right)$. This effect differed between the efficacious enzymes (time $\times$ treatment interaction: $F_{40,120}=8.2, P<0.001$ ), in that papaya latex and ficin were indistinguishable, as were papain and ficin, and stem bromelain was distinguishable from papaya latex, papain and ficin (Tukey's post-hoc test). These four enzymes all caused a significantly faster decline in motility than actinidain and Hanks' saline + cysteine, the latter treatments being indistinguishable from each other. In fact, the control worms, incubated either in Hanks' saline containing $16 \mathrm{mM}$ cysteine or Hanks' saline alone, showed no significant decline in activity over the 2-h period of observation.

When $R$. microstoma was incubated with the plant cysteine proteinases, there was a rapid decline in the motility of the worms (from 15 to $30 \mathrm{~min}$ post-incubation), resulting eventually in the death of these worms (fig. 2). This motility declined with time $\left(F_{8,120}=134.1\right.$, $P<0.001)$ and there was a highly significant main effect of treatment $\left(F_{4,15}=375.7, P<0.001\right)$. This effect differed between the efficacious enzymes (time $\times$ treatment interaction: $\left.F_{32,120}=9.4, P<0.001\right)$ in that papaya latex and ficin were indistinguishable, but differed from stem bromelain and actinidain (Tukey's post-hoc test). Although papaya latex and ficin were more effective than stem bromelain and actinidain, collectively all four enzymes produced a significantly different effect from that produced by both Hanks' saline + cysteine and Hanks' saline alone, the control worms in these latter treatments showing no significant decline in activity over the 2-h period of observation.

\section{Effects of plant cysteine proteinases on the worm surface at the light microscope level}

Papaya latex, papain and stem bromelain also caused damage to the cuticle of the hookworms that was evident at the light microscope level - consisting of blisters which perforated to release the internal structures, leading to the eventual death of the nematode by around 75-90 min after first exposure to the enzyme. This damage increased in intensity with time. Ficin also had this same effect against hookworms, but the damage progressed more slowly, possibly due to the lower enzyme concentration of $9 \mu \mathrm{M}$ instead of $>20 \mu \mathrm{M}$ for the other enzymes. Papaya latex, stem bromelain and ficin 


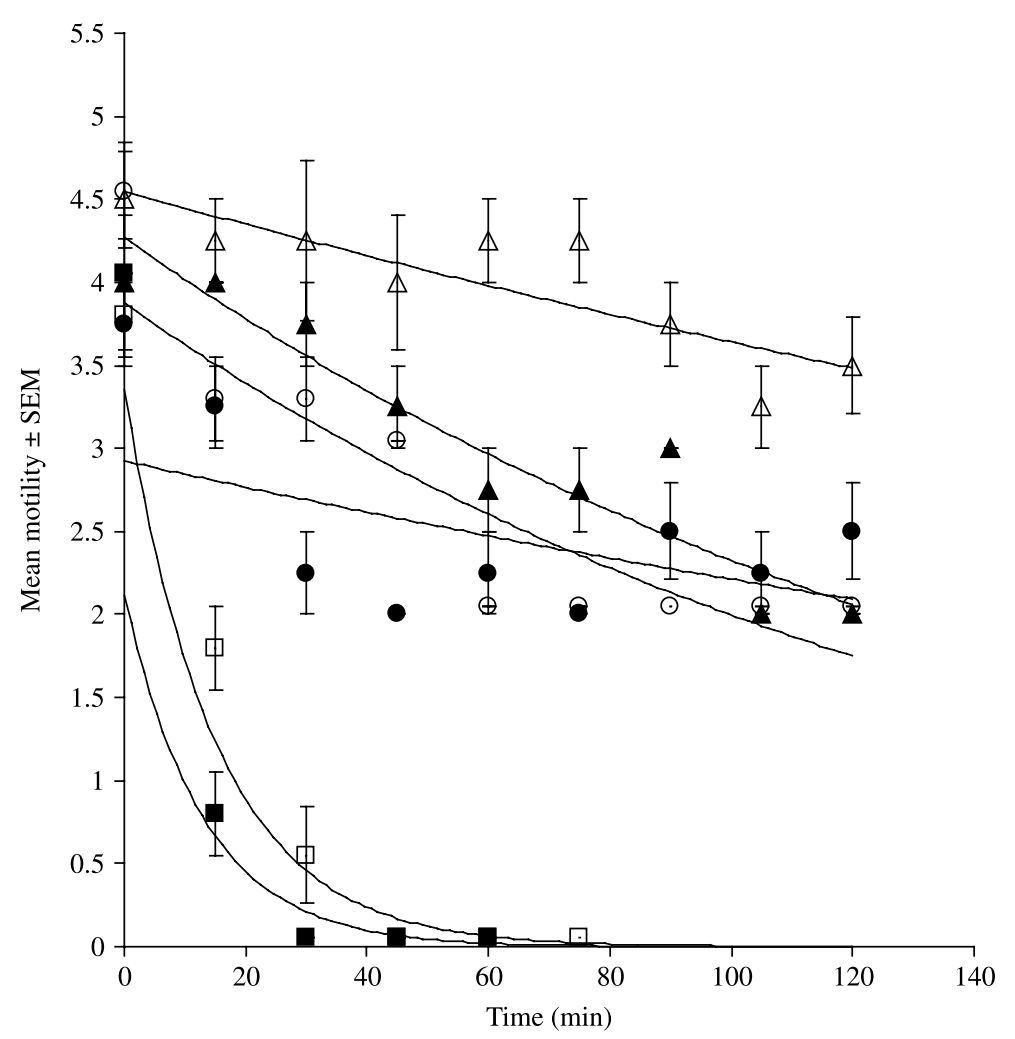

Fig. 2. The motility of Rodentolepis microstoma adult worms exposed to plant cysteine proteinases in vitro. Adult worms of R. microstoma were incubated with $25 \mu \mathrm{M}$ papaya latex, $9 \mu \mathrm{M}$ ficin, $90 \mu \mathrm{M}$ stem bromelain, $30 \mu \mathrm{M}$ actinidain (all in the presence of $16 \mathrm{mM}$ cysteine) or Hanks' saline with or without $16 \mathrm{mM}$ L-cysteine. Motility declined rapidly in the presence of all cysteine proteinases examined, while no significant change in activity was evident for the worms incubated in Hanks' saline, with or without cysteine. $\mathbf{\square}$, papaya latex; $\square$, ficin;

stem bromelain; $\bigcirc$, actinidain; $\mathbf{\Lambda}$, Hanks' + cysteine; $\triangle$, Hanks'. Error bars represent the standard error of the mean $(n=4)$.

also produced observable surface damage to the cestodes. The edges of the proglottids became blunter and thinner, and stem bromelain produced the formation of blisters at the anterior end of the worm from $75 \mathrm{~min}$ onwards. As with the hookworms, this damage increased over time, leading to the eventual death of the tapeworm (results not shown).

\section{Effects of plant cysteine proteinases on the worm surface at the scanning electron microscope level}

Scanning electron microscopy was used to examine the ultrastructural surface damage caused by these enzymes. Cuticular damage to A. ceylanicum (fig. 3) was very similar to that described earlier for $H$. polygyrus (Stepek et al., 2005), T. muris (Stepek et al., 2006) and P. muricola (Stepek et al., 2007a), in that it was progressive, with the initial formation of blisters, which perforated to release the internal structures of the worm, leading to complete digestion of the cuticle by $60 \mathrm{~min}$ in the presence of papain (fig. 3A), papaya latex (fig. 3B) or stem bromelain (fig. 3C). At the concentration used, ficin caused substantial digestion of the cuticle by $120 \mathrm{~min}$ (fig. 3D), and this was in accordance with the motility results, which showed that ficin was slower to affect the activity of hookworms than the other three enzymes examined, probably as a result of the lower active enzyme concentration of ficin used in these experiments. In marked contrast, on incubation of the worms with $30 \mu \mathrm{M}$ actinidain (fig. 3E) and Hanks' saline $+16 \mathrm{mM}$ cysteine (fig. 3F), the cuticle remained intact, with no visible damage whatsoever, even after $2 \mathrm{~h}$.

Cestodes do not have a cuticle but instead possess a tegument, which is a cytoplasmic syncytium limited by a trilaminate lipid membrane, as their external surface, and scanning electron microscopy revealed that the damage caused by the plant cysteine proteinases to R. microstoma was qualitatively different from that observed on the nematodes, but still clearly identifiable as a major disruption of the parasite's surface. As observed by scanning electron microscopy, the strobila of the cestode comprises a chain of proglottids which, on incubation with papaya latex or stem bromelain, became smaller and erupted in blisters over the surface (fig. 4). The digestion of the tegumental surface was evident by $30 \mathrm{~min}$ when the worms were incubated with $25 \mu \mathrm{M}$ papaya latex (fig. $4 \mathrm{~A}$ ) and by $60 \mathrm{~min}$ when the worms were incubated with $90 \mu \mathrm{M}$ stem bromelain (fig. 4B). In the presence of papaya 

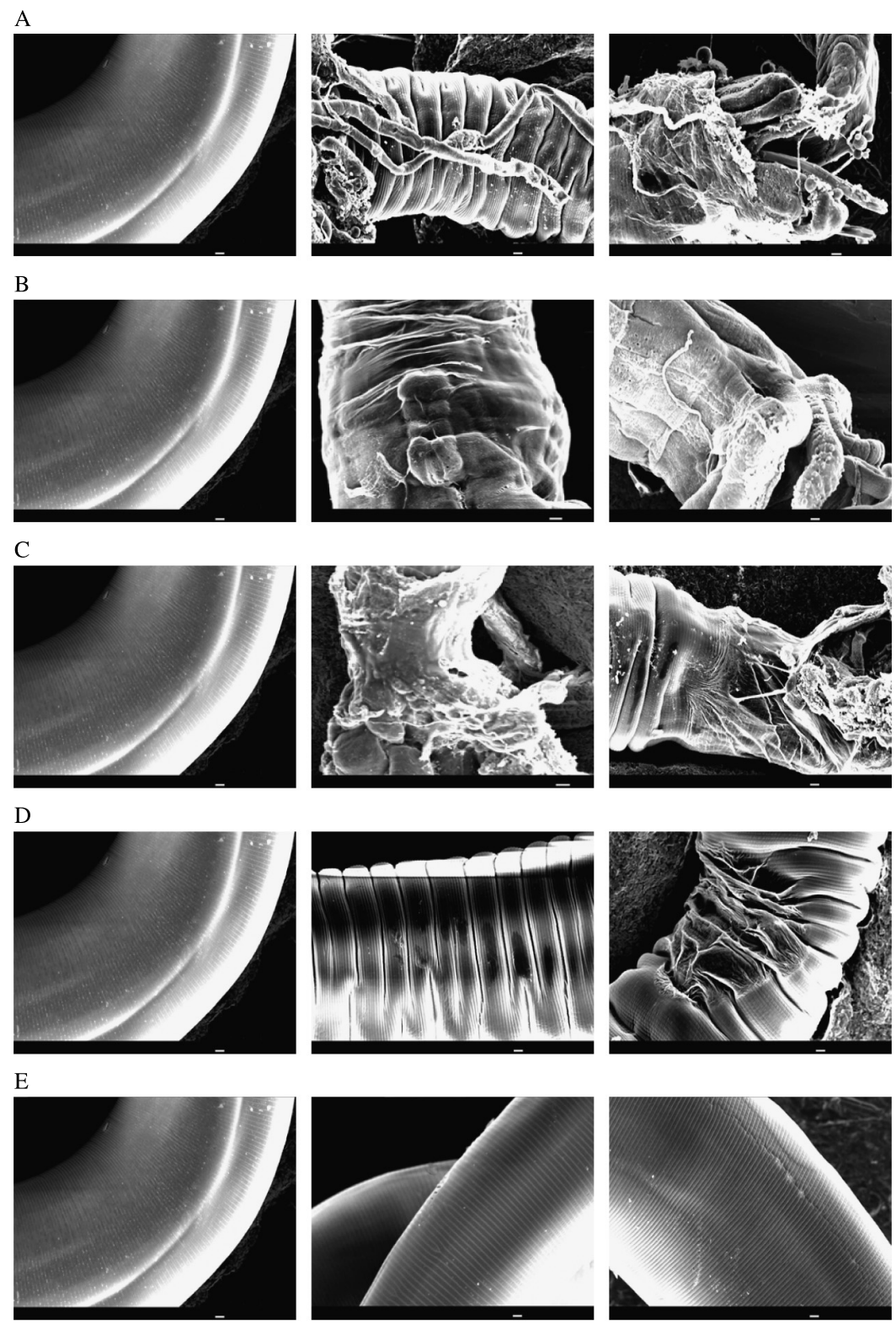

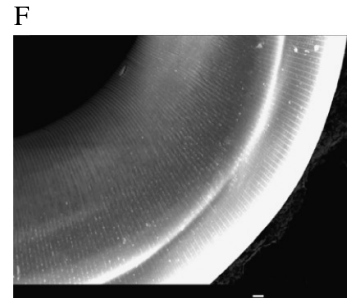

$0 \mathrm{~min}$

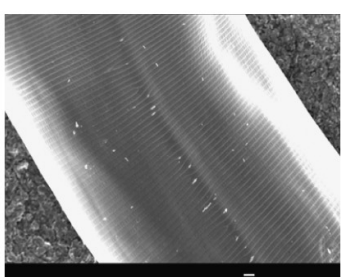

$60 \mathrm{~min}$

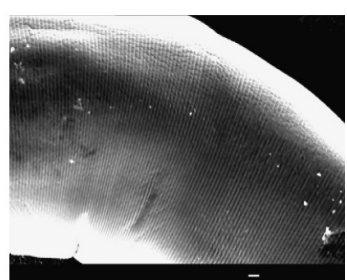

$120 \mathrm{~min}$

Fig. 3. Scanning electron microscopy of Ancylostoma ceylanicum adult worms incubated with or without plant cysteine proteinases in vitro. The micrographs were taken at equivalent points along the worm surface, near the mid-point. The digestion of the cuticle to expose the internal structures was evident by $60 \mathrm{~min}$ when the worms were incubated with $25 \mu \mathrm{M}$ papain (A), $25 \mu \mathrm{M}$ papaya latex (B) and $22.5 \mu \mathrm{M}$ stem bromelain (C), and by $120 \mathrm{~min}$ when the worms were incubated with $9 \mu \mathrm{M}$ ficin (D). The cuticle remained intact, with no visible damage whatsoever, even after $2 \mathrm{~h}$, on incubation of the worms with $30 \mu \mathrm{M}$ actinidain (E) and Hanks' saline $+16 \mathrm{mM}$ cysteine (F). Scale bar $=10 \mu \mathrm{m}$. 

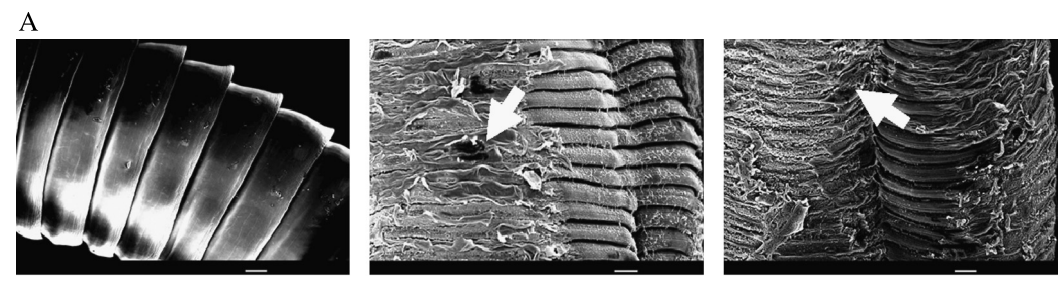

B
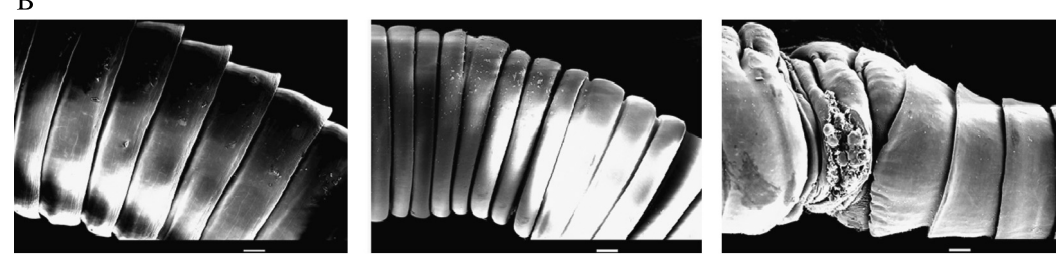

C
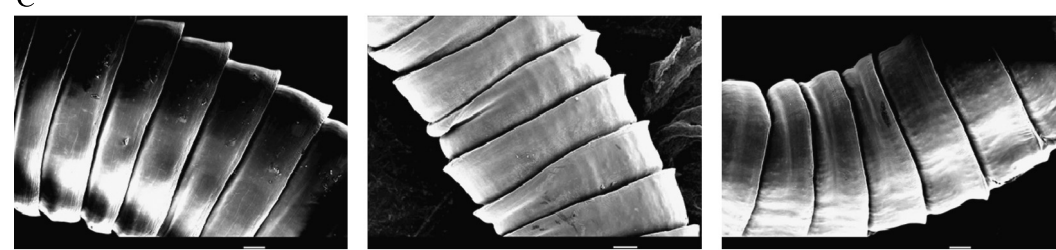

D

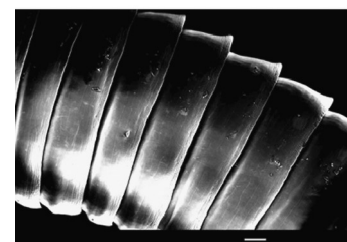

0 min

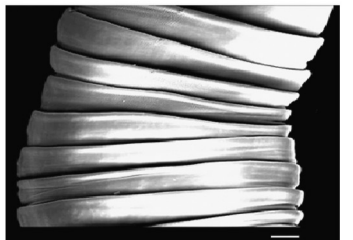

$30 \mathrm{~min}$

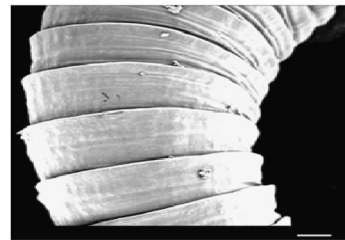

60 min

Fig. 4. Scanning electron microscopy of Rodentolepis microstoma adult worms incubated with or without plant cysteine proteinases in vitro. The micrographs were taken at equivalent points along the worm surface, near the mid-point. The digestion of the tegumental surface was evident by $30 \mathrm{~min}$ when the worms were incubated with $25 \mu \mathrm{M}$ papaya latex $(\mathrm{A})$ and by 60 min when the worms were incubated with $90 \mu \mathrm{M}$ stem bromelain (B). Later time points (not shown) exhibited similar damage, particularly with papaya latex, as the lesions (arrows in A) seen at 30 and $60 \mathrm{~min}$ increased in number by $120 \mathrm{~min}$. The tegument remained intact, with no visible damage, even after $2 \mathrm{~h}$, on incubation with $30 \mu \mathrm{M}$ actinidain $(\mathrm{C})$ and Hanks' saline $+16 \mathrm{mM}$ cysteine $(\mathrm{D})$. Scale bar $=100 \mu \mathrm{m}$.

latex, lesions (arrows in fig. 4A) appeared in the surface of the tegument, developed into deep perforations, and continued increasing in intensity over the 2-h incubation period (later time points not shown). In contrast, on incubation with $30 \mu \mathrm{M}$ actinidain (fig. 4C) and Hanks' saline containing $16 \mathrm{mM}$ cysteine (fig. $4 \mathrm{D}$ ), the tegument remained intact, with no visible damage, even after $2 \mathrm{~h}$.

\section{Discussion}

This study showed that, in vitro, cysteine proteinases from papaya, pineapple and fig caused substantial damage to the surface of parasitic nematodes (A. ceylanicum) and cestodes ( $R$. microstoma), which resulted in a significant reduction in the activity of these parasites. This effect was similar to that described previously for A. suum (Robbins, 1930; Berger \& Asenjo, 1939), H. polygyrus (Stepek et al., 2005), T. muris (Stepek et al., 2006) and P. muricola (Stepek et al., 2007a), indicating that plant cysteine proteinases have a broad spectrum of activity against parasitic helminths in vitro.

It would appear that the mechanism of action of plant cysteine proteinases against nematodes and cestodes is digestion of the parasite surface, releasing the internal structures, and leading to the death of the parasite. As for H. polygyrus, T. muris and P. muricola, actinidain from kiwi fruit was without effect on cuticular/tegumental damage. This is a remarkable finding given the similarity in enzyme structure and activity between actinidain and the other papain-like enzymes (Varughese et al., 1989, 1992) - they are virtually superimposable in the active-centre; however, there is evidence for differences in the characteristics and behaviour of their catalytic sites (Kowlessur et al., 1989). It is likely that the target molecules in the cuticle that are susceptible to attack by all the proteinases tested except actinidain, although undefined, are common components of the adult cuticle of the four species of GI nematode examined and of the adult 
tegument of $R$. microstoma. Despite the lack of any apparent effect on the tegumental structure, actinidain possessed some efficacy against the cestode, as shown by its effect on worm motility (fig. 2), perhaps indicating a different mechanism of action. However, in all cases, the enzymes from $C$. papaya latex, pure papain and ficin from $F$. carica latex appeared to have the greatest potency.

Therefore, it is evident that plant cysteine proteinases, with the exception of actinidain from kiwi fruit, have anthelmintic activity in vitro against a wide variety of GI helminths that include both nematodes and cestodes. Further analyses of the consequences of exposure to the enzymes on the cuticle and tegument are required to determine precisely the target molecules involved and to verify the selective effect of actinidain on the motility of cestodes. It is important to examine whether these natural enzymes have a detrimental effect against earlier life-cycle stages of cestodes, because earlier work has suggested that plant cysteine proteinases have no effect on the eggs of $H$. polygyrus or the structure and development of the L1 stage, or on the L3 stages of $H$. polygyrus, T. muris and P. muricola (Stepek et al., unpublished). However, these enzymes do affect the L4 stage of these nematodes in vitro, suggesting that there may be a difference between the cuticular structure and molecules of the pre-infective stages (eggs to L3) and the post-infective stages (L4 and adult).

To our knowledge, this is the first time that the anthelmintic effect of plant cysteine proteinases has been demonstrated against adult cestodes. Further investigation is required to determine whether these plant products are also efficacious against these cestodes in vivo, as has been shown previously for the GI nematodes, A. suum (Satrija et al., 1994), H. polygyrus (Satrija et al., 1995; Stepek et al., 2007b), T. muris (Stepek et al., 2006) and P. muricola (Stepek et al., 2007a). If this does prove to be the case, then cysteine proteinases from plants will have been shown to have a broad spectrum of activity against intestinal helminths, both in vitro and in vivo, reinforcing their suitability for development as a much-needed novel treatment for the control of GI helminths of humans and livestock.

\section{Acknowledgements}

This work was funded by a research grant from The Leverhulme Trust. We thank Simon Clifford and Tim Smith for excellent technical assistance in parasite maintenance and electron microscopy.

\section{References}

Anthony, J.-P., Fyfe, L. \& Smith, H. (2005) Plant active components - a resource for antiparasitic agents? Trends in Parasitology 21, 462-468.

Berger, J. \& Asenjo, C.F. (1939) Anthelmintic activity of fresh pineapple juice. Science 90, 299-300.

Berger, J. \& Asenjo, C.F. (1940) Anthelmintic activity of crystalline papain. Science 91, 387-388.
Garside, P. \& Behnke, J.M. (1989) Ancylostoma ceylanicum: observations on host-parasite relationship during primary infection. Parasitology 98, 283-289.

Geerts, S. \& Gryseels, B. (2000) Drug resistance in human helminths: current situation and lessons from livestock. Clinical and Microbiological Reviews 13, 207-222.

Giday, M., Asfaw, Z., Elmqvist, T. \& Woldu, Z. (2003) An ethnobotanical study of medicinal plants used by the Zay people in Ethiopia. Journal of Ethnopharmacology 85, 43-52.

Gill, J.H. \& Lacey, E. (1998) Avermectin/milbemycin resistance in trichostrongyloid nematodes. International Journal of Parasitology 28, 863-877.

Githiori, J.B., Höglund, J., Waller, P.J. \& Baker, R.L. (2003) Evaluation of anthelmintic properties of extracts from some plants used as livestock dewormers by pastoralist and smallholder farmers in Kenya against Heligmosomoides polygyrus infections in mice. Veterinary Parasitology 118, 215-226.

Hammond, J.A., Fielding, D. \& Bishop, S.C. (1997) Prospects for plant anthelmintics in tropical veterinary medicine. Veterinary Research Communications 21, 213-228.

Hounzangbe-Adote, S., Fouraste, I., Moutairou, K. \& Hoste, H. (2005) In vitro effects of four tropical plants on the activity and development of the parasitic nematode, Trichostrongylus colubriformis. Journal of Helminthology 79, 29-33.

Kaminsky, R. (2003) Drug resistance in nematodes: a paper tiger or a real problem? Current Opinion in Infectious Diseases 16, 559-564.

Kowlessur, D., O'Driscol, M., Topham, M., Templeton, W., Thomas, E.W. \& Brocklehurst, K. (1989) The interplay of electrostatic fields and binding interactions determining catalytic-site reactivity in actinidin. Biochemical Journal 259, 443-452.

Robbins, B.H. (1930) A proteolytic enzyme in ficin, the anthelmintic principle of leche de higueron. Journal of Biological Chemistry 87, 251-257.

Satrija, F., Nansen, P., Bjorn, H., Murtini, S. \& He, S. (1994) Effect of papaya latex against Ascaris suum in naturally infected pigs. Journal of Helminthology 68, 343-346.

Satrija, F., Nansen, P., Murtini, S. \& He, S. (1995) Anthelmintic activity of papaya latex against patent Heligmosomoides polygyrus infections in mice. Journal of Ethnopharmacology 48, 161-164.

Stepek, G., Buttle, D.J., Duce, I.R., Lowe, A. \& Behnke, J.M. (2005) Assessment of the anthelmintic effect of natural plant cysteine proteinases against the gastrointestinal nematode, Heligmosomoides polygyrus, in vitro. Parasitology 130, 203-211.

Stepek, G., Lowe, A.E., Buttle, D.J., Duce, I.R. \& Behnke, J.M. (2006) In vitro and in vivo anthelmintic efficacy of plant cysteine proteinases against the rodent gastrointestinal nematode, Trichuris muris. Parasitology 132, 681-689.

Stepek, G., Lowe, A.E., Buttle, D.J., Duce, I.R. \& Behnke, J.M. (2007a) Anthelmintic action of plant cysteine proteinases against the rodent stomach nematode, Protospirura muricola, in vitro and in vivo. Parasitology 134, 103-112. 
Stepek, G., Lowe, A.E., Buttle, D.J., Duce, I.R. \& Behnke, J.M. (2007b) The anthelmintic efficacy of plant-derived cysteine proteinases against the rodent gastrointestinal nematode. Heligmosomoides Polygyrus, in vivo. Parasitology 134, 1409-1419.

Varughese, K.I., Ahmed, F.R., Carey, P.R., Hasnain, S., Huber, C.P. \& Storer, A.C. (1989) Crystal structure of a papain-E-64 complex. Biochemistry 28, 1330-1332.

Varughese, K.I., Su, Y., Cromwell, D., Hasnain, S. \& Xuong, N. (1992) Crystal structure of an actinidin-E64 complex. Biochemistry 31, 5172-5176.
Waller, P.J. (1986) Anthelmintic resistance in nematode parasites of sheep. Agricultural Zoology Reviews 1, 333-373.

Waller, P.J., Bernes, G., Thamsborg, S.M., Sukura, A. Richter, S.H., Ingebrigtsen, K. \& Höglund, J. (2001) Plants as de-worming agents of livestock in the Nordic countries: historical perspective, popular beliefs and prospects for the future. Acta Veterinaria Scandinavica $42,31-44$.

(Accepted 1 February 2007) (C) 2007 Cambridge University Press 